\title{
Uporaba ProstorskiH KLJUČEv PRI UČEnCIH OSMEgA RAZREDA OSNOVNE ŠOLE
}

\section{Potrjeno / \\ Accepted \\ 19.03.2018 \\ Objavljeno / \\ Published \\ 21.6.2018}

Ključne besede: Likovna umetnost; Učni načrt za likovni umetnost; likovna didaktika; likovni prostor; prostorski ključi

Keywords: constructivism; handicrafts; mood; sewing.

UDK/UDC 37.091.2:7

\author{
Barbara LapuH ${ }^{1}$ JURIJ SELAN ${ }^{2}$
}

\author{
${ }^{1}$ Univerza v Ljubljani, Pedagoška fakulteta, Slovenija \\ 2 Univerza v Ljubljani, Pedagoška fakulteta, Slovenija \\ CORRESPONDING AUTHOR/KORESPONDENČNI AVTOR \\ jurij.selan@pef.uni-lj.si
}

Povzetek/Abstract V članku se ukvarjamo s specifičnim problemom, ki ga je mogoče zaznati pri urah likovne umetnosti $\mathrm{v}$ osmem in devetem razredu osnovne šole pri artikulaciji prostora na ploskvi z uporabo prostorskih ključev. Izkušnje kažejo, da učenci znanja o prostorskih ključih, ki ga usvojijo, kasneje v drugih likovnih nalogah pogosto ne izkažejo več. Ta problem smo podrobneje osvetlili z izvedbo kvalitativne raziskave pri 28 učencih osmega razreda osnovne šole, $\mathrm{v}$ kateri smo proučevali, kako učenci že naučeno znanje o prostorskih ključih uporabijo tudi v likovnih nalogah, pri katerih uporaba prostorskih ključev od njih ni eksplicitno zahtevana. Ena izmed ključnih ugotovitev raziskave je, da kar dve tretjini učencev $\mathrm{v}$ drugi risbi ni uporabilo znanja o prostorskih ključih, čeprav so ga izkazali v prvi risbi. To razkriva, da učenje prostorskih ključev, ki poteka zgolj nekaj ur pri predmetu likovna umetnost, ne vodi do tega, da bi učenci to znanje ponotranjili do te mere, da bi ga lahko spontano uporabljali.

The Usage of Visual Gradients at Eighth-graders In the article, we address an issue that can be observed in art lessons in the eighth and ninth grades of primary school in Slovenia. This issue is related to the ability to articulate the illusion of space in drawing by the use of visual gradients. Experience has shown that even though pupils have acquired knowledge of visual gradients, they fail to apply this knowledge in subsequent similar drawing tasks. Therefore, we performed a qualitative research study during art lessons in which we sought to analyse how eighth-graders (a sample of 28 pupils), once given the knowledge of visual gradients, use this knowledge in subsequent drawing assignments in which there is no explicit demand for the use of visual gradients. One of the key findings based on the results is that two-thirds of pupils did not apply their knowledge of visual gradients in the second drawing (despite showing it in first drawing). This reveals to us that a single exposure to visual gradients does not lead pupils to internalise the knowledge of visual gradients or to use it spontaneously.

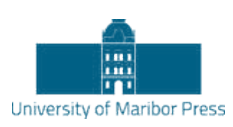




\section{Uvod}

»Razvoj prostorskega dojemanja je eden najpomembnejših ciljev likovne vzgoje» (Tomšič Čerkez, 2011, str. 31). Na tem spoznanju temelji tudi Učni načrt za likovno umetnost v osnovni šoli (Kocjančič idr., 2011). Duh in Vrlič (2003) utemeljujeta pomembnost razvijanja učenčevega razumevanja prostora $\mathrm{z}$ dejstvom, da ni poklicnega področja, na katerem ne bi bile potrebne razvite prostorske predstave. Ker je sposobnost dojemanja vizualnega prostora tesno povezana s sposobnostjo likovne artikulacije tega prostora, je tudi $\mathrm{v}$ učnem načrtu pri predmetu likovna umetnost $\mathrm{v}$ osmem razredu osnovne šole $\mathrm{v}$ okviru oblikovanja na ploskvi predvideno obravnavanje vsebine o upodabljanju iluzije prostora. Ko učitelj spremlja učence pri pouku likovne umetnosti, lahko prepoznava določene ponavljajoče se vzorce $\mathrm{v}$ njihovem likovnem izražanju. Nekateri so presenetljivi, druge pa je mogoče razložiti in utemeljiti na osnovi že raziskanih dejstev o otrokovem splošnem ali pa specifičnem razvoju, kot je na primer likovni. Eno takšnih zanimivih dejstev je mogoče opaziti pri učencih v osmem razredu in je povezano $z$ obravnavanjem vsebine o prostorskih ključih. Učenci to vsebino dobro usvojijo, kar večina uspešno izkaže $\mathrm{v}$ lastnem likovnem delu, vendar pa $\mathrm{v}$ kasnejših likovnih delih tega znanja ne uporabijo več ali pa ga le pomanjkljivo. Zato smo se natančneje poglobili $\mathrm{v}$ ta problem in poskušali to opažanje podkrepiti z raziskavo, $\mathrm{v}$ kateri smo zasledovali uspešnost uporabe prostorskih ključev v risbah učencev, prepričljivost artikulacije prostora na ploskvi v risbah in stopnjo v likovnem razvoju posameznika, s čimer je povezana tudi likovna kompozicija.

\section{Teoretična ižbodišra}

Prostorski ključ in zaznavne konstance

»Človek zaznava prostor s štirimi čuti: vidom, sluhom, tipom in kinestetično občutljivostjo. Od teh je najpomembnejši vid« (Pečjak, 2006, str. 65). Trstenjak (1978) pravi, da je človek »vidno« bitje, ker se pri orientaciji v prostoru najbolj zanaša na vid. Realni prostor, ki ga definirajo tri razsežnosti, je prostor, v katerem se gibljemo, zaznavamo predmete, njihove oblike in medprostor med njimi (Butina, 1997). Človek zaradi ustroja za to odgovornih organov brez težav obvladuje telo in se zato lahko orientira v prostoru, seveda ob predpostavki, da je zdrav. Izhajajoč iz dveh, za človeka temeljnih smeri - vertikalnosti človeškega telesa v stoječem položaju in horizontalnosti v ležečem položaju - lahko opredelimo tri navidezne, med seboj pravokotne ravnine: frontalna ravnina deli prostor na spredaj in zadaj, medialna na levo in desno, očesna pa na zgoraj in spodaj. To so ravnine prostorskega križa, ki je strukturirana oblika človekovega psihološkega prostora 
(Butina, 1997). Prostor definirajo odnosi med predmeti, torej tudi odnosi med človekom kot opazovalcem in predmeti. Človek je v več pogledih ključni element tega prostora, saj vzpostavlja fizične odnose s predmeti v prostoru, ga čustveno doživlja in v njem vzpostavljene odnose osmišlja (Butina, 2000). Realni prostor je za človeka skupaj z nepregledno množico predmetov mnogoterih oblik, velikosti, barv in tekstur izziv za likovno upodabljanje tako v prostoru kot na ploskvi. Likovni prostor izhaja iz t. i. naravno danega prostora oz. vizualnega psihološkega prostora, kot ga zaznava človek s pomočjo vidnega aparata na zavedni in nezavedni ravni (Muhovič, 2015). Tudi Butina (2000) pravi, da likovni prostor temelji na principih, po katerih človek zaznava in tudi dojema realni prostor. Bistvo problema upodabljanja realnega prostora na dvodimenzionalni ploskvi je, da se realni prostor od likovne ploskve razlikuje za eno dimenzijo. Tretjo dimenzijo lahko ustvarimo le navidezno, s pomočjo t. i. prostorskih ključev oz. globinskih vodil, zato je takšen prostor iluzija prostora. Prostorski ključi ali globinska vodila v zaznavi omogočajo izkušnjo globine, v likovnosti pa omogočajo artikulacijo iluzije globine na slikovni ploskvi (Butina, 1995). Po eni strani torej označujejo psihofiziološke temelje zaznavanja globine realnega prostora, hkrati pa tudi oblikotvorne temelje gradnje navidezne globine prostora na dvodimenzionalni površini. V praksi sicer ločujemo veliko različnih prostorskih ključev (npr. konvergenca linij, osvetljenost in osenčenost, delno prekrivanje oblik z oblikami, različna ostrina obrisov in detajlov glede na razdaljo, stopnjevanje velikosti, diferenciacija barvne intenzitete in njihove kombinacije ipd.), vendar pa je mogoče vse v osnovi kategorizirati v tri temeljne skupine: prostorski ključi na temelju prekrivanj, zvračanj in stopnjevanj. Te tri skupine prostorskih ključev temeljijo na ključnem zaznavnem pojavu, t. i. zaznavnih konstancah (Gillam, 2000; Sternberg, 2006; Kuroda, 1971; Garrigan in Kellman, 2008). Pogoj za mladostnikovo razumevanje in uporabo prostorskih ključev je torej ustrezen razvoj zavesti o zaznavnih konstancah. Značilno za pojav zaznavnih konstanc je, da možgani na osnovi pridobljenih izkušenj $v$ zaznavi ohranijo posamezne lastnosti pojmov in predmetov, tudi če pride do izrazitih sprememb v dražljajskih okoliščinah (Muhovič, 2015). Preprosto rečeno: kljub temu da se oblike lahko v prostoru prekrivajo, zvračajo ali stopnjujejo (po velikosti, barvi ipd.), ostajajo v naši zaznavi stabilne in konstantne, zato naša zaznava tolmači njihovo navidezno spreminjanje kot spremembo njihove prostorske orientacije in položaja. Vrst zaznavne konstance je toliko, kot je lastnosti oblik oz. likovnih spremenljivk. Rački (2010) na primer navaja konstanco barve (Foster, 2011), oblike (Sternberg, 2006), položaja (Goolkasian in Bojko, 2001), svetlosti (MacEvoy in Paradiso, 2001) in velikosti (Carlson, 2010). Za risanje je še posebej pomembna konstanca oblike, saj omogoča, da npr. kocko prepoznamo kot kocko, čeprav se nam nikoli ne kaže kot skupek kvadratov, temveč kot skupek trapezov (prav tam). Zaznavne konstance 
niso človekova prirojena značilnost, pač pa poteka njihov razvoj zlagoma s pridobivanjem izkušenj in razvojem pojmovanja (če od rojstva slepemu povrnemo sposobnost gledanja, sprva ne bo še ničesar zares videl, ker se morajo zaznavne konstance v njegovi vidni zaznavi šele vzpostaviti) (Pečjak, 2006). Fenomen zaznavne konstance človeku ekonomizira življenje, ker omogoča stabilnost v njegovih zaznavah, saj se lastnosti fizikalnih dražljajev, ki jim je človek ves čas izpostavljen, neprestano spreminjajo. Butina (1997) zato pravi, da so to zaznavni procesi, ki nam omogočajo, »da lahko sploh mislimo in spoznavamo svet, in predmeti $\mathrm{v}$ njem morajo ohranjati svoje značilnosti, da jih lahko povežemo $s$ pomeni in jih tako spremenimo v pojme« (str. 78).

\section{Likouna sintaksa in likouni jerik}

Z likovnim prostorom je neločljivo povezana tudi likovna kompozicija, tako v procesu zaznavanja kot tudi v likovni artikulaciji. Ker sintaksa likovnega prostora in sintaksa likovne kompozicije temeljita na vzpostavljanju odnosov med oblikami ter med oblikami in formatom, vplivata druga na drugo. Posledično so tudi prostorski ključi, s katerimi prikažemo iluzijo globine prostora, povezani s kompozicijskimi principi. Likovni prostor in likovna kompozicija sta del sintaktične ravni likovnega jezika. Vsak jezik ima komunikacijsko, spoznavno in ustvarjalno funkcijo. Tako tudi likovni jezik v komunikacijskem smislu najprej služi kot sredstvo komunikacije ustvarjalca $\mathrm{s}$ samim seboj in nato tudi $\mathrm{z}$ okolico, $\mathrm{v}$ spoznavnem smislu predstavlja sredstvo za spoznavanje vidnega sveta ter $\mathrm{v}$ poetičnem smislu (gr. poiein - ustvarjati) sredstvo za ustvarjanje novega likovnega sveta. Tako kot v besednem jeziku so te funkcije tudi v likovnem jeziku mogoče na osnovi sistema pravil - slovnice - ki omogoča artikulacijo in interpretacijo likovnega jezika (Selan, 2014). Likovni jezik torej artikulira odnose $\mathrm{v}$ prostoru na likovnojezikovnih ravneh: fotološki, morfološki, sintaktični in semantični. Posebna specifika likovnega jezika se pri tem kaže prav na sintaktični ravni, ki je, za razliko od sintakse besednega jezika, dvonivojska - hkrati poteka na dveh podravneh, na ravni sintakse likovnega prostora in na ravni sintakse likovne kompozicije. Ko namreč likovnik razporeja oblike v iluzijo prostora, jih hkrati razporeja tudi po površini slikovne ploskve. In obratno, ko jih razporeja po površini formata, jih hkrati ureja tudi $\mathrm{v}$ globino prostora. Gradnjo likovne kompozicije omogočajo kompozicijski principi, gradnjo likovnega prostora pa prostorski ključi, oboji pa so med seboj neločljivo prepleteni (Selan, 2013). Sintaktična raven likovnega jezika torej zajema strategije, ki opredeljujejo, kako oblike hkrati prepričljivo gradijo likovni prostor in hkrati tvorijo tudi likovno kompozicijo. 


\section{Likouni jezile in likouni razvoj}

Tako kot se zaznavne konstance lahko vzpostavijo le skozi postopno izkušnjo, tako se otrok tudi sposobnosti likovne artikulacije prostora ne more zgolj naučiti, pač pa jo mora $\mathrm{v}$ procesu postopne likovne izkušnje in likovnega razvoja ponotranjiti. Razumevanje likovnosti kot jezikovnega pojava na to še posebej opozarja. »Namen učenja likovnega jezika je aktivirati sposobnost, da človek spontano razvije generativno gramatiko, ki mu omogoča spoznavanje, poetično izražanje in razumevanje $\mathrm{v}$ likovnem jeziku. Likovna kompetenca je torej sposobnost, ki omogoča, da zna nekdo generirati in interpretirati likovni izraz na vsaki izmed ravni generativne gramatike likovnega jezika ter se s tem v likovnem jeziku izražati in ga razumeti« (Selan, 2014, str. 378). Tako kot pri izražanju v besednem jeziku se posameznik tudi v likovnem jeziku obstoja pravil nujno niti ne zaveda, a se kljub temu lahko spontano in suvereno izraža, če je likovno gramatiko med procesom razvoja likovne jezikovne izkušnje v procesu likovnega udejstvovanja ponotranjil. Spontano ponotranjanje likovnega jezika se pri otroku začne s prvo čačko v zgodnjem otroštvu. Kasneje se spontanemu učenju likovnega jezika pridruži še namensko učenje, ki ga je z odraščanjem vedno več, spontanega pa vedno manj. Otrok se likovnega jezika hitro uči, če le ima možnost kontinuirane likovne aktivnosti in je deležen ustrezne spodbude skozi vse otroštvo. Ponotranjenje likovnega jezika je za otroka pomembno z več vidikov: s pomočjo risbe ozavesti vsa nova odkritja iz vidnega sveta; s spoznavanjem zakonitosti prostora ponotranji zakonitosti zaznavnih konstanc, na katerih temelji razumevanje prostorskih ključev; likovni jezik za otroka služi kot orodje za komunikacijo s samim seboj in drugimi; omogoča tudi razvoj analitičnega in sintetičnega mišljenja (Selan, 2014). Sposobnost uporabe prostorskih ključev in artikulacije prostora na ploskvi pri mladostnikih je mogoče najbolje spremljati na področju risbe. Vsakega izmed nas spremlja risba že od zgodnjega otroštva (Rački, 2010), saj je likovno izražanje potreba vsakega otroka (Pečjak, 2006). Risanje je pomemben segment človekovega duševnega in telesnega razvoja (Rački, 2010). Likovno izražanje otroka se razvija pod vplivom vzporednih procesov dozorevanja in učenja, ki so med seboj odvisni, vsak pa ima tudi svoje zakonitosti. Rezultat teh procesov so spremembe $\mathrm{v}$ telesnem, psihomotoričnem, kognitivnem, emocionalnem in socialnem razvoju otroka (Duh in Vrlič, 2003; Karlavaris in Berce Golob, 1991). Otrok pri likovnem izražanju v likovni izdelek vnaša svoje interese, želje, pričakovanja in tudi strahove (Pečjak, 2006). Ker temelji likovno izražanje na prostoru in prostorskih odnosih, je najpomembnejši segment pri ponotranjenju likovnega jezika prav razvoj artikulacije likovnega prostora (Selan, 2014) in likovne kompozicije, ki se v vsaki razvojni fazi otroške risbe kaže v specifičnem načinu vzpostavljanja odnosov med oblikami ter med oblikami in formatom. Likovni razvoj otroka poteka skozi določene standardne faze, ki jih 
navajajo najrazličnejši avtorji (Piaget in Inhelder, 1956; Karlavaris in Berce Golob, 1991; Matthews, 1992; Duh in Vrlič, 2003; Grgurić in Jakubin, 1996; Cox, 2005; Freeman, 1980; Jolley, 2010; Lowenfeld in Brittain, 1987; Luquet, 1913, 1927; Strauss, 2007; Tanay, 1988; Thomas in Silk, 1990; Waber in Holmes, 1985; Wenham, 2003; Marjanovič Umek, 2011; Marjanovič Umek in Zupančič, 2004).

Ko $\mathrm{v}$ otrokovem likovnem razvoju ena razvojna faza mine, nova spoznanja spremenijo njegov način upodabljanja prostora (Frelih, 2012). Pri tem je zelo pomembna spodbuda okolja (staršev, vzgojiteljev, učiteljev), vendar ne na način, da se otroka sili v prehitro prehajanje skozi faze razvoja, pač pa na način spodbujanja, da otrok v posamezni razvojni fazi likovno artikulacijo čim bolj poglobi (Selan, 2014). Tudi prikazovanje prostora $\mathrm{v}$ risbi sledi določenim zakonitostim, ki so vezane na razvoj in starost otroka (Golomb, 1992). Prikazovanje prostora sprva temelji na otrokovih predstavah o tem, kar upodablja, in ne le na tem, kar vidi, zato otrok $\mathrm{v}$ risbo pogosto vključi tudi tisto, česar na predmetu ni. Med devetim in enajstim letom preidejo otroci na razvojno stopnjo, ki jim omogoča vzpostaviti zavest o zaznavnih konstancah in jim pri prikazovanju prostora omogoča upoštevanje perspektive, razporejanje elementov glede na njihove medsebojne odnose in usklajevanje različnih pogledov (Golomb, 1992). V tem obdobju dozorevanja zato želi večina otrok $\mathrm{v}$ risbi prikazati globino prostora (Matthews, 2003). Pri upodabljanju predmetov uporabljajo poševno projekcijo, ukvarjajo pa se tudi že s prikazovanjem volumna s pomočjo senčenja (Berce Golob, 1993). Karlavaris in Berce Golob (1991) zato pravita, da je razvijanje prikazovanja prostora pri učencih treba spremljati in spodbujati brez pretiranega usmerjanja, saj so šele po dvanajstem letu sposobni uporabiti postopek perspektivnega risanja.

\section{Metoda}

Opredelitev problema in cilj raziskave

Otroci med devetim in enajstim letom preidejo na razvojno stopnjo, ki jim omogoča razviti ustrezno zavest o zaznavnih konstancah, te pa so predpogoj za razumevanje prostorskih ključev (Golomb, 1992). Zato je učna vsebina o upodabljanju iluzije prostora s pomočjo prostorskih ključev po učnem načrtu za osnovno šolo smiselno umeščena v osmi razred (Kocjančič idr., 2011). Toda izkušnje kažejo, da učenci znanja o prostorskih ključih, ki ga usvojijo pri učnih urah likovne umetnosti, kasneje $\mathrm{v}$ podobnih likovnih nalogah ne izkažejo več. Ta problem smo zato želeli podrobneje raziskati z izvedbo kvalitativne raziskave med učenci osmega razreda osnovne šole. Zastavili smo si tri raziskovalna vprašanja:

RV1: Prvo je vezano na trajnost in ponotranjenost znanja o prostorskih ključih: Ali in kako učenci že naučeno znanje o prostorskih ključih uporabijo 
tudi $\mathrm{v}$ likovnih nalogah, pri katerih uporaba prostorskih ključev ni eksplicitno zahtevana?

RV2: Drugo je vezano na sposobnost in skladnost utemeljitve učencev, katere prostorske ključe mislijo, da so uporabili, katere pa so tudi zares uporabili: Ali se utemeljitve učencev glede uporabe prostorskih ključev skladajo z njihovo dejansko uporabo?

RV3: Tretje je vezano na kompleksnost in celovitost likovne artikulacije prostora: Ali učenci, ki v risbi uporabijo več prostorskih ključev, tudi izkažejo bolj celovito artikulacijo likovnega prostora?

\section{Vrorec}

Vzorec je bil neslučajnostni namenski in zajema dva oddelka učencev osmega razreda osnovne šole ene izmed ljubljanskih osnovnih šol. Od 38 učencev je obe za analizo potrebni risbi izdelalo 28 učencev.

\section{Postopki pridobivanja podatkov}

Izvedli smo kvalitativno raziskavo, ki je potekala $\mathrm{v}$ dveh stopnjah. Nastale risbe so v raziskavi predstavljale glavni vir podatkov za analiziranje. Prva dejavnost je bila učna ura, pri kateri smo učence poučevali o prostorskih ključih. V prvi likovni nalogi, $\mathrm{v}$ kateri so učenci upodobili iluzijo prostora $\mathrm{z}$ uporabo prostorskih ključev, so imeli za izhodišče slovensko ljudsko bajko o nastanku Blejskega jezera. $\mathrm{Na}$ osnovi vsebine so si poljubno izbrali motiv. Risali so s tušem in trsko na gladko stran risalnega lista formata A3. Pri prvi likovni nalogi so morali uporabiti vsaj štiri različne prostorske ključe. Odločili so se lahko za konvergenco linij, delno prekrivanje, odsebno senco, stopnjevanje velikosti, diferenciacijo obrisov in detajlov, nizanje ravnin drugo nad drugo, obvezno pa so morali uporabiti grafično modelacijo. Med likovnim izražanjem smo z učenci komunicirali, jih spodbujali in po potrebi dodatno razložili morebitne nejasnosti. Učenci so na koncu na vsak izdelek napisali, katere prostorske ključe so v posamezni risbi uporabili. Po preteku treh mesecev so pri drugi dejavnosti učenci dobili novo likovno nalogo na področju risanja - izbirali so lahko med naslovoma Sprehod po domišljijski pokrajini in Piknik v Tivoliju, risali pa so s svinčnikom na pisarniški papir formata A4. Za razliko od prve naloge učencev nismo posebej spodbujali k uporabi prostorskih ključev, saj smo želeli ugotoviti njihovo spontano uporabo; delali so povsem samostojno. Po koncu so učenci na risbo zopet zapisali, katere prostorske ključe so uporabili. 


\section{Postopki obdelave podatkov}

$\mathrm{V}$ dveh korakih raziskave je vsak od 28 učencev izdelal dve risbi. Skupno 56 izdelkov smo nato ocenili trije ocenjevalci: magistrica profesorica poučevanja likovne pedagogike, univerzitetni profesor likovne teorije ter univerzitetni profesor risanja in slikanja. Dva ocenjevalca imata bogate izkušnje iz preizkusov likovne nadarjenosti na univerzitetni ravni ter iz sodelovanja $\mathrm{v}$ najrazličnejših komisijah za ocenjevanje likovnih del otrok (natečaji, bienala ipd.). Likovne izdelke smo ocenili na dva načina, kvantitativno in kvalitativno: po eni strani smo šteli uporabljene prostorske ključe in jih točkovali (vsak uporabljen prostorski ključ smo ovrednotili z eno točko). Po drugi strani pa smo ocenjevali celovito uspešnost artikulacije likovnega prostora v risbi (uspešna ali neuspešna artikulacija prostora). Pri tem smo upoštevali likovnojezikovne kriterije za ugotavljanje kompleksnosti likovnih izdelkov učencev (Pibernik, Podobnik in Selan, 2017). Izdelke smo analizirali in primerjali glede na posameznega učenca. Pridobljene podatke smo deskriptivno statistično obdelali. Zaradi majhnosti vzorca ugotovitve veljajo za proučevani primer.

\section{Rezultati}

Raziskovalno vprašanje 1

Likovna analiza risb iz prvega koraka raziskave je pokazala, da je 19 učencev, kar je $70 \%$ oz. dve tretjini celotnega vzorca, v risbah prikazalo vsaj štiri prostorske ključe. Po preteku treh mesecev se je pri drugi likovni nalogi v drugem koraku raziskave pokazalo, da je takih učencev precej manj, le 10, kar je $36 \%$ oz. le dobra tretjina vzorca. Koliko prostorskih ključev so učenci uporabili v prvi in drugi risbi, je razvidno iz tabele 1 , uporabo posameznega prostorskega ključa $\mathrm{v}$ obeh risbah pa prikazuje tabela 2 .

Tabela 1: Število učencev (absolutna in relativna frekvenca), ki je v prvi in drugi risbi uporabilo od 0 do 7 prostorskih kljucerv

\begin{tabular}{lccccccccc}
\hline \multicolumn{2}{c}{ Št. prostor. ključev } & 0 & 1 & 2 & 3 & 4 & 5 & 6 & 7 \\
\hline \multirow{2}{*}{$\begin{array}{l}\text { Prva risba } \\
\mathrm{N}=28\end{array}$} & $\mathrm{~N}$ & 0 & 0 & 2 & 7 & 6 & 8 & 3 & 2 \\
\cline { 2 - 10 } & $\%$ & 0 & 0 & 7 & 25 & 21 & 29 & 11 & 7 \\
\hline Druga risba & $\mathrm{N}$ & 1 & 6 & 7 & 4 & 6 & 1 & 3 & 0 \\
$\mathrm{nyyyyyyyy}=28$ & $\%$ & 4 & 21 & 25 & 14 & 21 & 4 & 11 & 0 \\
\hline
\end{tabular}




\begin{tabular}{|c|c|c|c|c|c|c|c|c|c|c|c|c|}
\hline \multirow[t]{2}{*}{$\begin{array}{l}\text { Prostorski } \\
\text { ključi }\end{array}$} & \multicolumn{2}{|c|}{ 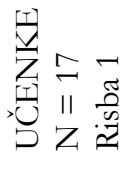 } & \multicolumn{2}{|c|}{ 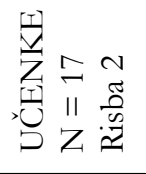 } & \multicolumn{2}{|c|}{ 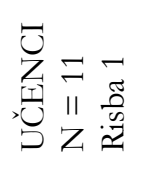 } & \multicolumn{2}{|c|}{ 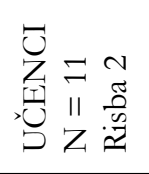 } & \multicolumn{2}{|c|}{ 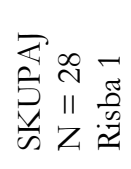 } & \multicolumn{2}{|c|}{ 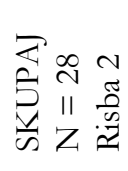 } \\
\hline & $\mathrm{N}$ & $\%$ & $\mathrm{~N}$ & $\%$ & $\mathrm{~N}$ & $\%$ & $\mathrm{~N}$ & $\%$ & $\mathrm{~N}$ & $\%$ & $\mathrm{~N}$ & $\%$ \\
\hline Konvergenca linij & 7 & 41 & 5 & 29 & 2 & 18 & 5 & 45,5 & 9 & 32 & 10 & 36 \\
\hline Prekrivanje & 16 & 94 & 14 & 82 & 9 & 82 & 7 & 64 & 25 & 89 & 21 & 75 \\
\hline Grafična modelacija & 14 & 82 & 4 & 23,5 & 5 & 45,5 & 2 & 18 & 19 & 68 & 6 & 21 \\
\hline Senca & 9 & 53 & 4 & 23,5 & 5 & 45,5 & 1 & 9 & 14 & 50 & 5 & 18 \\
\hline Stopnjevanje velikosti & 14 & 82 & 10 & 59 & 9 & 82 & 5 & 45,5 & 23 & 82 & 15 & 54 \\
\hline Jasnost obrisov in detajlov & 8 & 47 & 2 & 12 & 3 & 27 & 4 & 36 & 11 & 39 & 6 & 21 \\
\hline Nizanje ravnin & 14 & 82 & 9 & 53 & 7 & 64 & 6 & 54,5 & 21 & 75 & 15 & 54 \\
\hline
\end{tabular}

V tabeli 2 so zbrani podatki o tem, koliko učenk in koliko učencev je uporabilo posamezni prostorski ključ $\mathrm{v}$ prvi in $\mathrm{v}$ drugi risbi. Navedene so tudi skupne vrednosti za učenke in učence. V celotnem vzorcu jih je največ uporabilo prostorski ključ prekrivanje oblik - pri prvi risbi $89 \%$, pri drugi pa $75 \%$, kar kaže, da so učenci in učenke ta prostorski ključ razumeli in ga tudi ozavestili. Drugi najpogosteje uporabljen prostorski ključ je pri obojih stopnjevanje velikosti; pri prvi risbi ga je uporabilo $82 \%$, pri drugi pa $54 \%$ vseh učencev in učenk. Zelo podobno razmerje je tudi pri nizanju ravnin drugo nad drugo - $75 \%$ vseh ga je uporabilo v prvi, $54 \%$ pa v drugi risbi. Največja razlika med prvo in drugo risbo je ugotovljena pri grafični modelaciji - v prvi risbi jo je uporabilo $68 \%$ učencev in učenk, v drugi pa le $21 \%$. To kaže na slabše poznavanje tega globinskega vodila in se sklada $z$ ugotovitvami raziskav, da se senčenje pojavi šele $\mathrm{v}$ kasnejšem obdobju otrokovega likovnega razvoja (Matthews, 1999). Precejšnja razlika je tudi pri uporabi odsebne sence, saj jo je $\mathrm{v}$ prvi risbi upodobila le polovica učencev in učenk, $\mathrm{v}$ drugi pa slaba petina. $\mathrm{V}$ prvi risbi je bila najmanjkrat uporabljena konvergenca linij (32\%), v drugi pa odsebna senca $(18 \%)$. Zanimiva je tudi primerjava rezultatov po spolu, ki pri prvi risbi pokaže, da so učenke večino prostorskih ključev uporabile večkrat kot učenci, razen stopnjevanja velikosti, ki so ga uporabili oboji enako $(82 \%)$. Pri prvi risbi je razlika največja pri grafični modelaciji (učenke $82 \%$, učenci 45,5\%), pri drugi risbi pa so ta prostorski ključ tako učenke kot učenci slabše uporabili (učenke 23,5 \%, učenci $18 \%$ ). V drugi risbi so učenci večkrat kot učenke uporabili konvergenco linij (učenci 45,5\%, učenke $29 \%$ ) in diferenciacijo jakosti obrisov in detajlov (učenci 36 $\%$, učenke $12 \%$ ), učenke pa so bile bolj kot učenci dosledne pri prekrivanju elementov (učenke $82 \%$, učenci $64 \%$ ), nekoliko bolje pa so tudi stopnjevale velikost. 
Raziskovalno vprašanje 2

Kot utemeljitev uporabe prostorskih ključev pri vrednotenju izdelkov so učenci na vsak izdelek napisali, katere prostorske ključe so v posamezni risbi uporabili. V tabeli 3 so zbrani podatki o tem, koliko učenk in koliko učencev je pri vrednotenju utemeljilo uporabo posameznega prostorskega ključa $\mathrm{v}$ prvi in v drugi risbi. Hkrati so navedene tudi skupne vrednosti za učenke in učence.

Tabela 3: Pogostost utemeljitve (absolutna in relativna frekvenca) uporabe prostorskih ključev pri vrednotenju prvih in drugih risb

\begin{tabular}{|c|c|c|c|c|c|c|c|c|c|c|c|c|}
\hline \multirow[t]{2}{*}{ Prostorski ključi } & \multicolumn{2}{|c|}{ 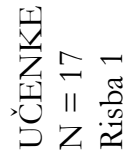 } & \multicolumn{2}{|c|}{ 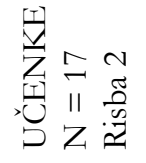 } & \multicolumn{2}{|c|}{ 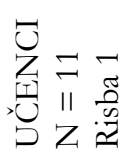 } & \multicolumn{2}{|c|}{ 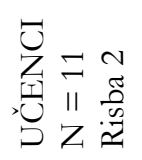 } & \multicolumn{2}{|c|}{ 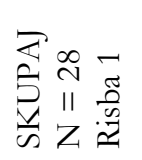 } & \multicolumn{2}{|c|}{ 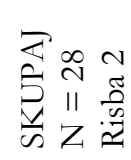 } \\
\hline & $\mathrm{N}$ & $\%$ & $\mathrm{~N}$ & $\%$ & $\mathrm{~N}$ & $\%$ & $\mathrm{~N}$ & $\%$ & $\mathrm{~N}$ & $\%$ & $\mathrm{~N}$ & $\%$ \\
\hline Konvergenca linij & 14 & 82 & 2 & 12 & 2 & 18 & 2 & 18 & 16 & 57 & 4 & 14 \\
\hline Prekrivanje & 14 & 82 & 10 & 59 & 6 & 54,5 & 4 & 36 & 20 & 71 & 14 & 50 \\
\hline Grafična modelacija & 15 & 88 & 1 & 6 & 4 & 36 & 2 & 18 & 19 & 68 & 3 & 11 \\
\hline Senca & 10 & 59 & 2 & 12 & 3 & 27 & 2 & 18 & 13 & 46 & 4 & 14 \\
\hline Stopnjevanje velikosti & 10 & 59 & 4 & 23,5 & 5 & 45,5 & 1 & 9 & 15 & 54 & 5 & 18 \\
\hline Jasnost obr. in detajlov & 10 & 59 & 2 & 12 & 2 & 18 & 0 & 0 & 12 & 43 & 2 & 7 \\
\hline Nizanje ravnin & 2 & 12 & 2 & 12 & 1 & 9 & 0 & 0 & 3 & 11 & 2 & 7 \\
\hline
\end{tabular}

Pri prvi risbi pri učenkah najbolj odstopajo navedbe pri konvergenci linij - navedlo jo je $82 \%$ učenk, uporabilo pa pol manj - in pri nizanju ravnin drugo nad drugo, kjer pa so precej nižje navedbe (12\%) od v risbah uporabljenega (82\%). Pri učencih je največja razlika nastala pri nizanju ravnin drugo nad drugo, saj jih je le $9 \%$ ta ključ utemeljilo, uporabilo pa ga je $64 \%$ učencev. Precej manjkrat, kot so dejansko uporabili globinsko vodilo, so ga navedli še v primeru prekrivanja in stopnjevanja velikosti. Delež teh odstopanj gotovo odpade na nedosledno upoštevanje navodila glede navedbe uporabljenih prostorskih ključev, ki so ga učenke bolj upoštevale kot učenci. Pri drugi risbi je očitno, da so zaradi preteka daljšega časa od obravnavanja te vsebine učenci pozabili izraze za posamezni prostorski ključ; glede na uporabljene prostorske ključe so jih navajali zelo pomanjkljivo. Pri tem so bile učenke vseeno nekoliko bolj vestne in so si pomagale z zapisom v zvezku.

\section{Raziskovalno vprašanje 3}

Pri kvalitativni presoji celovite gradnje prostora v risbah učencev smo na podlagi pregledovanja, razčlenjevanja in primerjanja izdelkov formirali tri kategorije: zelo uspešna, zadovoljiva in neuspešna artikulacija prostora. Zelo uspešna pomeni 
prepričljivo upodobitev prostora, ki daje vtis celovitosti. Zadovoljiva artikulacija prostora pomeni, da je $\mathrm{v}$ risbi mogoče zaznati tretjo dimenzijo, neuspešna artikulacija pa je opredelitev za neprepričljiv vtis globine in za ploskovitost risbe, torej odsotnost navidezne tretje dimenzije. V skupino uspešnih smo nato razvrstili tako učence in učenke, ki so zelo uspešno artikulirali prostor, kot tudi tiste, ki so prostor artikulirali zadovoljivo.

Tabela 4: Pogostost (absolutna in relativna frekvenca) uspešne in neuspešne artikulacije prostora v prvi in drugi risbi

\begin{tabular}{lcccc}
\hline & \multicolumn{2}{c}{ Uspešna artikulacija prostora } & Neuspešna artikulacija prostora \\
\cline { 2 - 5 } & $\mathrm{N}$ & $\%$ & $\mathrm{~N}$ & $\%$ \\
\hline Prva risba & 14 & 50 & 14 & 50 \\
\hline Druga risba & 11 & 39 & 17 & 61 \\
\hline Prva in druga risba & 3 & 9 & 4 & 14 \\
\hline
\end{tabular}

Iz tabele 4 je razvidno, da je $\mathrm{z}$ vidika artikulacije navideznega prostora $\mathrm{v}$ prvi risbi iluzijo prostora uspešno upodobilo 14 učencev in učenk, kar je $50 \%$ oz. polovica vzorca, v drugi risbi pa le 11 učencev in učenk, kar predstavlja le $39 \%$ oz. dve petini vzorca. Iz tretje vrstice je razvidno, koliko učencev in učenk je bilo pri obeh risbah uspešnih in koliko jih je imelo v obeh izrazite težave pri tvorbi globine prostora.

Tabela 5: Śtevilo (absolutna in relativna frekvenca) uporabljenih prostorskih ključev pri učenkah in učencih, ki so uspeřno/ neuspeřno artikulirali prostor

\begin{tabular}{|c|c|c|c|c|c|c|c|c|c|c|}
\hline \multirow{2}{*}{\multicolumn{3}{|c|}{$\begin{array}{c}\text { Artikulacija } \\
\text { Prostora }\end{array}$}} & \multicolumn{8}{|c|}{ Število uporabljenih prostorskih ključev } \\
\hline & & & \multirow{2}{*}{$\begin{array}{l}0 \\
0 \\
\end{array}$} & \multirow{2}{*}{$\begin{array}{l}1 \\
0\end{array}$} & \multirow{2}{*}{$\begin{array}{l}2 \\
0 \\
\end{array}$} & \multirow{2}{*}{$\begin{array}{l}3 \\
0 \\
\end{array}$} & \multirow{2}{*}{$\begin{array}{l}4 \\
3 \\
\end{array}$} & \multirow{2}{*}{$\begin{array}{l}5 \\
7 \\
\end{array}$} & \multirow{2}{*}{$\begin{array}{l}6 \\
2 \\
\end{array}$} & \multirow{2}{*}{$\begin{array}{l}7 \\
2 \\
\end{array}$} \\
\hline \multirow{2}{*}{\multicolumn{2}{|c|}{$\begin{array}{l}\text { Uspešna (risba 1) } \\
\mathrm{N}=14\end{array}$}} & $\mathrm{~N}$ & & & & & & & & \\
\hline & & $\%$ & 0 & 0 & 0 & 0 & 21 & 50 & 14 & 14 \\
\hline \multirow{2}{*}{\multicolumn{2}{|c|}{$\begin{array}{l}\text { Neuspešna (risba 1) } \\
\mathrm{N}=14\end{array}$}} & $\mathrm{~N}$ & 0 & 0 & 2 & 7 & 3 & 1 & 1 & 0 \\
\hline & & $\%$ & 0 & 0 & 14 & 50 & 21 & 7 & 7 & 0 \\
\hline \multirow{2}{*}{\multicolumn{2}{|c|}{$\begin{array}{l}\text { Uspešna (risba 2) } \\
\mathrm{N}=11\end{array}$}} & $\mathrm{~N}$ & 0 & 0 & 0 & 1 & 5 & 2 & 3 & 0 \\
\hline & & $\%$ & 0 & 0 & 0 & 9 & 45 & 18 & 27 & 0 \\
\hline \multirow{2}{*}{\multicolumn{2}{|c|}{$\begin{array}{l}\text { Neuspešna (risba 2) } \\
N=17\end{array}$}} & $\mathrm{~N}$ & 1 & 7 & 6 & 2 & 1 & 0 & 0 & 0 \\
\hline & & $\%$ & 6 & 41 & 35 & 12 & 6 & 0 & 0 & 0 \\
\hline \multirow{4}{*}{$\begin{array}{l}\text { Uspešna (obe risbi) } \\
\mathrm{N}=3\end{array}$} & \multirow{2}{*}{ Risba 1} & $\mathrm{~N}$ & 0 & 0 & 0 & 0 & 0 & 1 & 1 & 1 \\
\hline & & $\%$ & 0 & 0 & 0 & 0 & 0 & 33 & 33 & 33 \\
\hline & \multirow{2}{*}{ Risba 2} & $\mathrm{~N}$ & 0 & 0 & 0 & 0 & 0 & 0 & 3 & 0 \\
\hline & & $\%$ & 0 & 0 & 0 & 0 & 0 & 0 & 100 & 0 \\
\hline \multirow{4}{*}{$\begin{array}{l}\text { Neuspešna (obe risbi) } \\
N=4\end{array}$} & \multirow{2}{*}{ Risba 1} & $\mathrm{~N}$ & 0 & 0 & 1 & 2 & 1 & 0 & 0 & 0 \\
\hline & & $\%$ & 0 & 0 & 25 & 50 & 25 & 0 & 0 & 0 \\
\hline & \multirow{2}{*}{ Risba 2} & $\mathrm{~N}$ & 1 & 3 & 0 & 0 & 0 & 0 & 0 & 0 \\
\hline & & $\%$ & 25 & 75 & 0 & 0 & 0 & 0 & 0 & 0 \\
\hline
\end{tabular}


Iz tabele 5 je razvidno, koliko prostorskih ključev so uporabili učenci, ki so uspešno artikulirali prostor, in koliko učenci, ki pri tem niso bili uspešni. Ugotovimo lahko, da je število uporabljenih prostorskih ključev povezano z uspešnostjo celovite, prepričljive gradnje prostora, saj so tisti učenci, ki so dobro upodobili tretjo dimenzijo, v povprečju uporabili tudi več prostorskih ključev $(M=5,2)$ kot tisti, ki so bili pri gradnji prostora neuspešni $(M=3,4)$. Ta razlika je po pričakovanju še bolj opazna ob primerjavi $\mathrm{v}$ obeh risbah izrazito uspešne in izrazito neuspešne artikulacije prostora.

Primerjava obeh risb posameznega učenca pokaže, da so v obeh risbah iluzijo prostora suvereno prikazali le trije, kar je razvidno iz primera št. 1 (sliki 1 in 2).

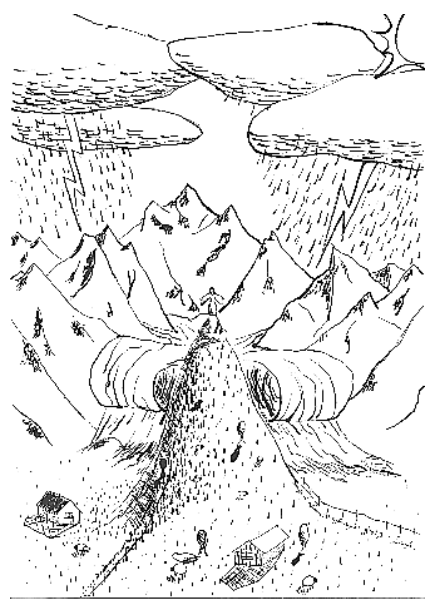

Slika 1: Primer št. 1 (prva risba) - dobro artikuliran navidezni prostor

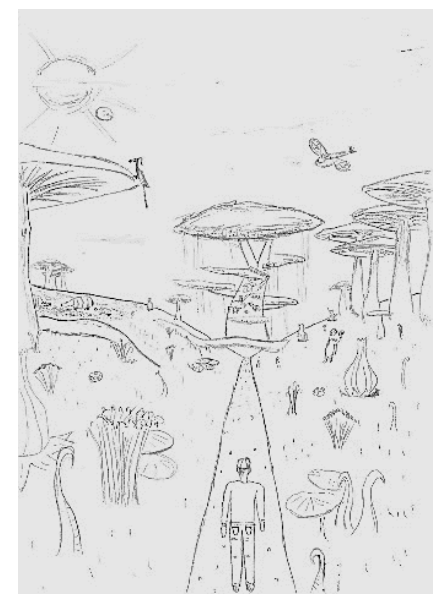

Slika 2: Primer št. 1 (druga risba) - dobro artikuliran navidezni prostor 
Osem učencev je $\mathrm{v}$ drugi risbi bolje upodobilo navidezni prostor kot $\mathrm{v}$ prvi, od tega trije nekoliko bolje, pet pa precej bolje, kot kaže primer št. 2 (sliki 3 in 4). Za te učence je bila verjetno ključna okoliščina, da posebnih navodil za izvedbo druge risbe ni bilo, zato niso bili obremenjeni z definiranjem in izvedbo določenega števila prostorskih ključev. To pomeni, da imajo ti učenci vsaj do neke mere ponotranjeno zavest o artikulaciji prostora. Seveda je mogoč razlog tudi motiv, ki jim je na prvi pogled ponujal več svobode, k sproščenosti izvedbe pa je gotovo prispevala tudi tehnika risanja s svinčnikom, ki jo učenci radi uporabljajo in so je bolj vajeni kot tuša in trske.

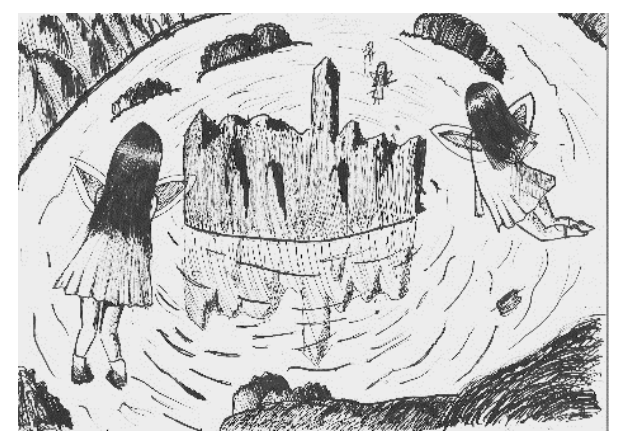

Slika 3: Primer št. 2 (prva risba) - slabše artikuliran navidezni prostor

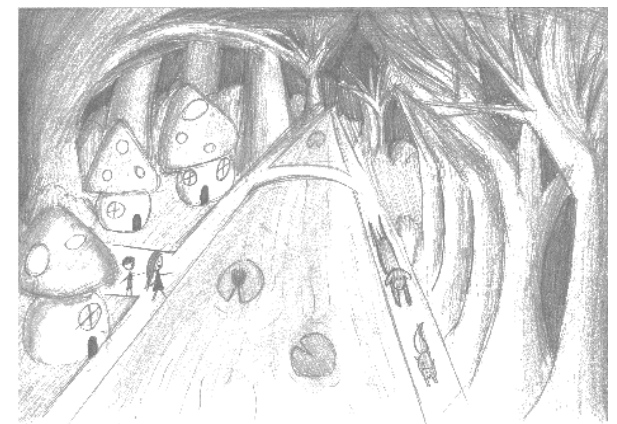

Slika 4: Primer št. 2 (druga risba) - dobro artikuliran navidezni prostor

Primer št. 3 (sliki 5 in 6) je od enega od štirih učencev, ki so imeli pri obeh risbah velike težave pri upodabljanju iluzije prostora. Poleg umanjkanja prostorskega dojemanja odnosov in posledično razumevanja in uporabe prostorskih ključev kot temeljnega načina gradnje prostorske iluzije je pri teh posameznikih očitna bodisi izrazita negotovost pri likovnem izražanju bodisi nezainteresiranost za katero koli likovno področje. 


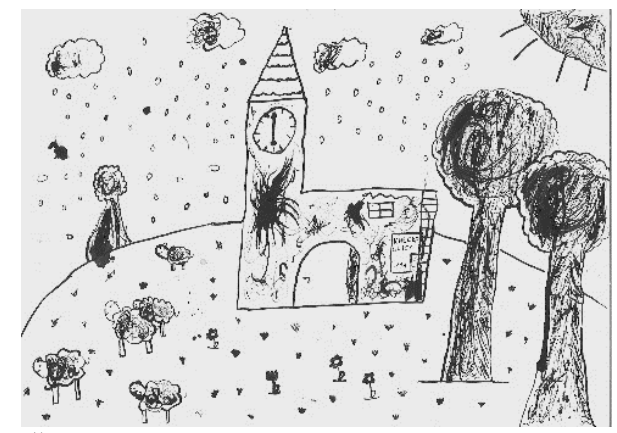

Slika 5: Primer št. 3 (prva risba) - zelo slabo artikuliran navidezni prostor

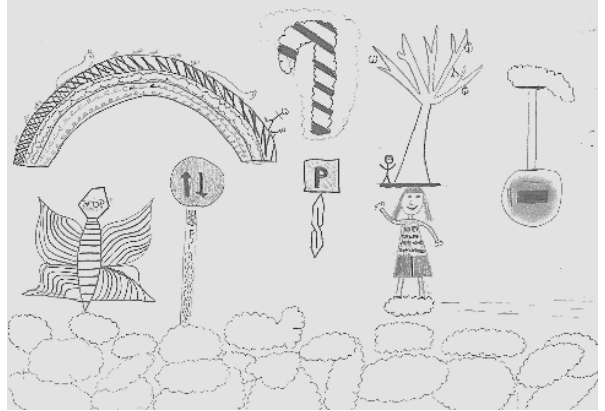

Slika 6: Primer št. 3 (druga risba) - zelo slabo artikuliran navidezni prostor

Za raziskavo najpomembnejši podatek je, da je trinajst učenk in učencev, kar je skoraj polovica vzorca, iluzijo prostora $\mathrm{v}$ prvi risbi prikazalo bolje kot $\mathrm{v}$ drugi. Primer št. 4 (sliki 7 in 8) razkriva, kako velika je pri tem lahko razlika v prostorski kompleksnosti med prvo in drugo risbo. Pri teh učencih je očitno, da so v prvem koraku raziskave s pomočjo usvojenega znanja o prostorskih ključih v prvi risbi sicer zadovoljivo upodobili navidezni prostor, toda njihova druga risba dokazuje, da teh načel likovnega jezika niso ponotranjili, zato niso tudi spontano artikulirali prostora, ko se to od njih ni zahtevalo.

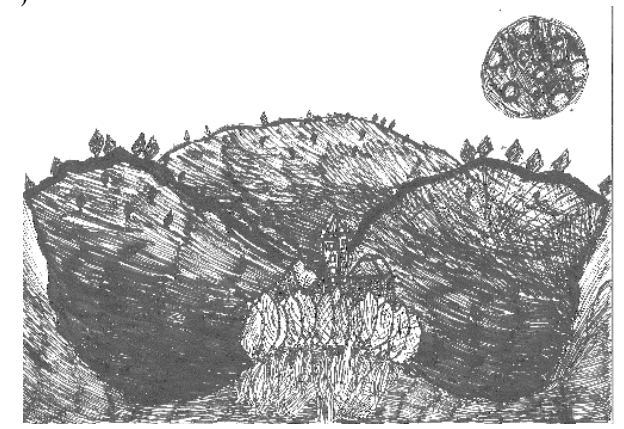

Slika 7: Primer št. 4 (prva risba) - dobro artikuliran navidezni prostor 


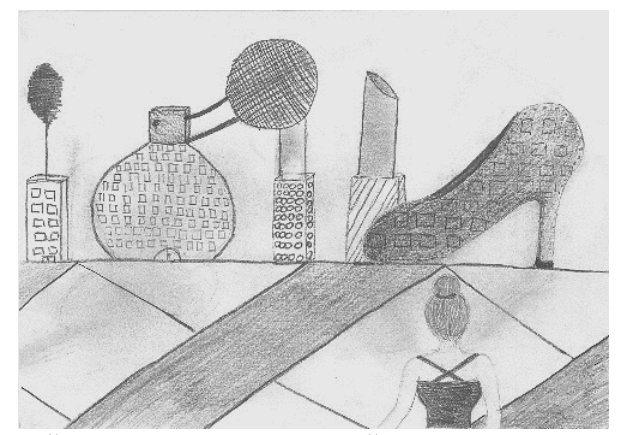

Slika 8: Primer št. 4 (druga risba) - slabše artikuliran navidezni prostor

\section{Interpretacija}

Ponotranjenost in celovitost znanja o likovnem prostoru

$\mathrm{S}$ proučitvijo in analizo uporabe prostorskih ključev v likovnih delih učencev smo dobili precej izčrpne podatke za interpretacijo glede na izhodiščni problem in cilj raziskave ter na zastavljena raziskovalna vprašanja. Zaradi majhnosti vzorca rezultati sicer veljajo le za obravnavani vzorec, vendar pa se je na osnovi dobljenih podatkov slika o problemu kljub temu precej razjasnila in odprla kompleksno problematiko, ki je povezana z naravo likovnega jezika oz., specifično, likovne sintakse. $\mathrm{V}$ raziskavi smo uspešno uporabo prostorskih ključev $\mathrm{v}$ risbah učencev merili na eni strani tako, da smo šteli prisotnost posameznih prostorskih ključev (tabeli 1 in 2). Poleg tega pa so tudi učenci na risbe zapisali, katere prostorske ključe mislijo, da so uporabili v risbi. S tem smo dobili podatke za prvo (RV1) in drugo raziskovalno vprašanje (RV2). V odnosu do RV1 se je izkazalo, da se je uporaba prostorskih ključev po treh mesecih precej zmanjšala $-\mathrm{v}$ risbah $\mathrm{v}$ drugem koraku raziskave smo namreč našteli precej manj uporabljenih prostorskih ključev kot $\mathrm{v}$ risbah iz prvega koraka raziskave. V odnosu do RV2 pa smo ugotovili dvoje. Da so učenci za kakšen prostorski ključ večkrat zapisali, da so ga uporabili, čeprav ga niso (ter obratno, da so kakšnega v resnici uporabili, pa ga niso zapisali), ter da se je v drugem koraku prav tako bistveno zmanjšalo število zapisanih prostorskih ključev. To kaže, da se sposobnost uporabe prostorskih ključev le deloma pokriva z njihovim teoretičnim zavedanjem, kar nakazuje, da teoretično zavedanje načel likovnega jezika ne pomeni nujno uspešne uporabe teh načel, ter obratno, da nezavedanje nekaterih načel ne pomeni nujno, da teh načel nekdo ne zna uporabljati. Podobno kot velja za vsak jezik, velja torej tudi za likovni jezik. Jezikovna načela je treba ponotranjiti (zato lahko postanejo nezavedna), ne pa se jih zgolj teoretično zavedati. Prav zaradi te ugotovitve se je ob »štetju« prostorskih ključev v risbah učencev razkril naslednji bistveni problem, ki je povezan s tretjim raziskovalnim vprašanjem (RV3) in vpliva tudi na prvo raziskovalno vprašanje 
(RV1). Štetje posameznih prostorskih ključev in presojanje njihove skladnosti z zapisi učencev o tem, kateri prostorski ključ so uporabili, daje vpogled v usvajanje konkretne vsebine, torej posamičnih prostorskih ključev, ne pa tudi vpogleda $\mathrm{v}$ to, kako so uporabljeni prostorski ključi prepleteni z ostalimi načeli likovne artikulacije $\mathrm{v}$ kompleksno prostorsko in kompozicijsko celoto. Zato smo v risbah presojali tudi likovno celovitost in uspešno artikulacijo likovnega prostora $\mathrm{v}$ risbi kot celoti (tabeli 4 in 5). Šele ta celovitost je tista, ki nakazuje razliko, ki je za likovno izražanje bistvena, namreč razliko med poznavanjem posameznih prostorskih ključev kot izoliranih likovnojezikovnih načel in njihovim ponotranjenjem znotraj likovnega jezika. Skratka: to, da učenec pozna in zna uporabiti posamezen prostorski ključ kot samostojen princip, je podobno, kot da zna v besednem jeziku spregati ali sklanjati glagol ali samostalnik. Ko se učimo tujega jezika, se spreganja in sklanjanja sicer lahko zelo dobro naučimo, toda če tega procesa ne bomo ponotranjili kot dela širše jezikovne celote, ga ne bomo znali spontano in konsistentno uporabljati v jezikovni praksi, in torej jezika pravzaprav sploh ne bomo znali. Podobno je tudi s prostorskimi ključi (in vsemi likovnojezikovnimi principi). Primeri učencev, ki so v prvem koraku izkazali relativno dobro znanje o prostorskih ključih, v drugem pa ne, kažejo na to, da so v prvem koraku prostorske ključe sicer uporabili navidezno pravilno, vendar ne skladno z ostalimi prostorskimi ključi in nekonsistentno povezano v likovno celoto. Zato se tudi znanje o teh prostorskih ključih pri teh učencih ni ponotranjilo, torej prepletlo $\mathrm{z}$ ostalimi likovnojezikovnimi načeli $\mathrm{v}$ celovito likovno sposobnost. Posledično ti učenci principov gradnje likovnega prostora niso uporabili spontano $\mathrm{v}$ drugem koraku raziskave, ko tega od njih nismo zahtevali in ko se tega niso več »učili«. Primerjava tabel 1 in 4 nam torej pove, da čeprav je več kot štiri prostorske ključe v prvi risbi uporabilo 19 učencev, jih je bilo pri celoviti gradnji prostora uspešnih 14. In čeprav je v drugi risbi več kot štiri prostorske ključe uporabilo 10 učencev, jih je bilo pri tem uspešnih 11. To pomeni, da neka korelacija med številom uporabljenih prostorskih ključev in uspešno artikulacijo prostora sicer obstaja (trije učenci, ki so bili uspešni v obeh risbah, so uporabili več kot pet prostorskih ključev), vendar pa sama količina uporabe prostorskih ključev še ni nujno odraz uspešne in celovite gradnje likovnega prostora.

\section{Likouni razuoj kot razuoj likounega jezika}

Dodaten problem se razkrije, če ob presoji problema sposobnosti uporabe prostorskih ključev upoštevamo tudi likovni razvoj učencev, kakor se kaže v pridobljenih risbah. Stanje, ki se pri tem razkrije, je prav pereče. Pri tej starosti bi morali namreč vsi učenci že kazati izrazito sposobnost spontane uporabe vsaj nekaterih prostorskih ključev, npr. prekrivanja in stopnjevanja velikosti. To 
razvojno stopnjo lahko ugotovimo ob sliki 9, kaže pa se v sproščenosti, spontanosti, predvsem pa v konsistentnosti upodobitve prostora. Da pri nekaterih učencih zavest o likovnem prostoru pri tej starosti še ni vzpostavljena do ravni, ki bi jim omogočala spontano in uspešno artikulacijo prostora, dokazuje slika $10, \mathrm{v}$ kateri so oblike razporejene linearno, večinoma po načelu največje jasnosti - torej med njimi ni prekrivanja ali pa so prikazane $z$ različnih pogledov. V teh risbah je jasno prepoznavna pasovno vezana kompozicija, z zaprtostjo formata navzgor in navzdol ter $\mathrm{z}$ odprtostjo $\mathrm{v}$ levo in desno, ta način artikulacije likovnega prostora in kompozicije pa je značilen za faze likovnega razvoja, ki bi jih moral učenec osmega razreda osnovne šole že zdavnaj nadgraditi.

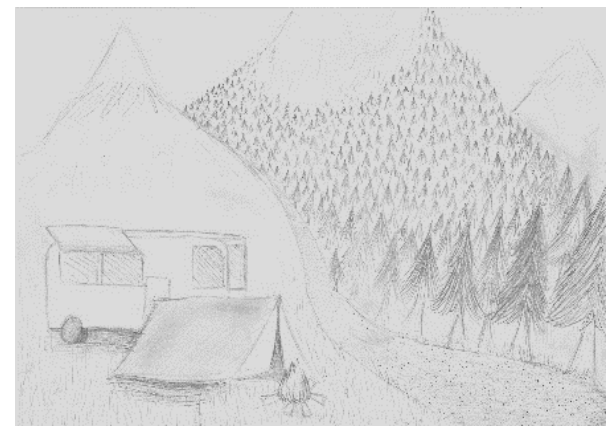

Slika 9

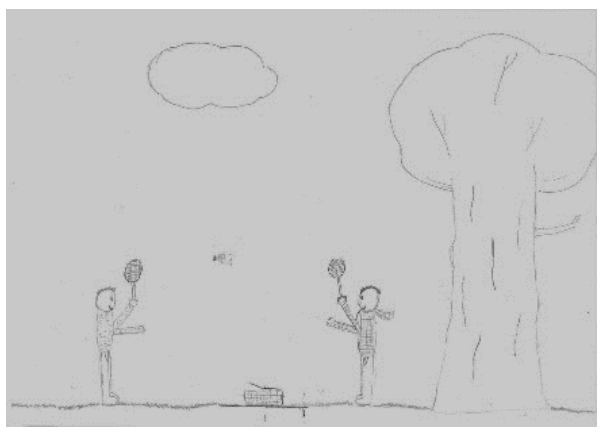

Slika 10

Ali tako likovno razvojno razliko med učencema pri isti starosti res lahko pripišemo zgolj prirojeni likovni sposobnosti? Če razumemo likovno izražanje kot jezikovni pojav, se kot problem razkrije naslednje. Učenec, ki je naredil sliko 10, verjetno ni imel dovolj priložnosti, da bi svojo likovno jezikovno sposobnost ustrezno razvil. Jezikovna sposobnost se mora namreč sprožiti v jezikovnem okolju in z jezikovno aktivnostjo v tem okolju (kot kažejo primeri volčjih otrok). Če se to ne zgodi dovolj zgodaj in dovolj pogosto, potem se jezik pomanjkljivo razvija. Učitelj lahko v tem 
procesu zgolj pomaga in usmerja, ne more pa seveda $v$ nekaj učnih urah nadomestiti pomanjkanja na ravni temeljne jezikovne izkušnje. Matthews (1999) ugotavlja, da otrok $\mathrm{z}$ eksperimentiranjem doseže spretnost $\mathrm{v}$ prostorski prezentaciji $\mathrm{v}$ daljšem obdobju, ki traja vse od zgodnjega otroštva. Otrok pri uvajanju globinskih odnosov $\mathrm{v}$ risbo uporablja različne prostorske ključe, kot npr. prekrivanje, stopnjevanje velikosti in kasneje konvergenco, ki jih raziskuje ločeno, pozneje pa jih začne svobodno uporabljati in združevati, vendar pa na določeni stopnji potrebuje usmeritev in pomoč učitelja ali mentorja (prav tam). Da je doseganje ciljev pri likovni vzgoji dolgotrajen proces, trdita tudi Duh in Vrlič (2003). Otrok, ki je z veseljem in zavzetostjo risal vse predšolsko obdobje in tudi med šolanjem, je pri reprezentaciji prostora precej suveren, čeprav, kot pravi Matthews (1999), najstnik tridimenzionalnosti predmetov in prostora še ne prikaže $\mathrm{v}$ pravi perspektivi, pa ploskve sestavlja tako, da doseže dovolj prepričljivo predmetnost. Iz tega sledi, da pomeni obravnavana vsebina za tega učenca koristno informacijo o poimenovanju in tehnični izvedbi posameznega prostorskega ključa kot tudi temelj za napredek in nadaljnji likovni razvoj, ni pa ključnega pomena za učinkovit prikaz iluzije prostora. Nasprotno pa za učenca, ki občutka za oblikovanje prostora ni razvijal že od zgodnjega otroštva, ki ni imel veselja ali želje po tovrstnem ustvarjanju, morda pa tudi ne spodbude, ta vsebina pomeni le faktografsko znanje, ki gre prav hitro $\mathrm{v}$ pozabo. To, da je bila $\mathrm{v}$ artikulaciji prostora uspešna le polovica vzorca v prvi risbi in še manj v drugi, je torej zaskrbljujoče. Nekaj podobnega bi bilo, če bi na ravni znanja besednega jezika sintakso znala uporabljati le polovica učencev osmega razreda osnovne šole. O primerjavi in odnosu med učenjem besednega in likovnega jezika govori tudi Matthews (2003), ki pravi, da otroci oblikujejo vizualni jezik, še preden dobro spregovorijo. Ko se otrok uči govoriti, znova in znova vadi glasove sam zase, saj se mu zdijo glasovne aktivnosti zanimive. Zanima ga, kako se glasovi sestavljajo, da dobijo določen pomen. Pri risanju je situacija popolnoma enaka. Otroci raziskujejo, ponavljajo, kombinirajo, se igrajo z oblikami, vzorci, barvami, črtami in gibi. K temu početju pa pogosto dodajo še glasove, ki so usklajeni $z$ ritmom risanja - kot da bi si risbo »narekovali« (Matthews, 1999). Risanje je kompleksna dejavnost, ki vključuje otrokovo zaznavanje, gibanje in mišljenje (Trawick-Smith, 1997). Še en dokaz o prepletanju in povezanosti verbalnega in likovnega izražanja je po mnenju Matthewsa (1999) dejstvo, da otrok v začetku ne razlikuje med besedo in sliko/risbo in ju zato pogosto med seboj kombinira, meša. $\mathrm{Na}$ ta način poskuša na risalni površini ugotoviti razlike in podobnosti med figurativnimi podobami in dogovorjenimi pisnimi znaki. Otrok v svojem raziskovanju dveh semiotičnih sistemov njune meje namenoma razširi in ju med seboj prepleta, saj imata oba načina zanj enako pomemben status (prav tam).

\section{Zaključek}


Otrok spoznava svet in se pripravlja za vstop v odraslost tudi preko likovnega jezika, v katerem se od ranega otroštva likovno izraža in ki ga korak za korakom osvaja v razvojno pogojenem zaporedju. Ob tem se postavlja vprašanje, kaj se je na likovni razvojni poti zgodilo s tistimi učenci $\mathrm{v}$ raziskavi, ki so $\mathrm{v}$ risbi izkazali podpovprečne rezultate pri artikulaciji prostora na ploskvi. Možnih razlogov je precej, npr. odsotnost ustrezne spodbude za likovno izražanje $\mathrm{v}$ otroštvu, nerazumevanje otroškega likovnega izraza otroku najbližjih oseb, napačno pedagoško usmerjanje otrokovega likovnega delovanja, ukvarjanje $\mathrm{z}$ drugimi prostočasnimi dejavnostmi, ki jih npr. ponujajo nove tehnologije, vključenost otroka v številne zunajšolske dejavnosti ipd. Kateri razlog ali razlogi v posameznem primeru prevladajo, je nemogoče ali zelo težko opredeliti. Z gotovostjo pa lahko trdimo, da se bo posameznik, ki likovnega jezika ni spontano ponotranjil v kontinuiranem likovnoustvarjalnem procesu $\mathrm{v}$ predšolskem in zgodnjem osnovnošolskem obdobju, tega naučil s precej več napora in namenskega učenja (Selan, 2014). Posebej je treba izpostaviti tudi dejstvo, da so učenci od šestega do devetega razreda deležni ene same ure likovnega pouka na teden. To pa je verjetno tudi srž marsikaterega problema, s katerim se soočamo pri likovnem pouku, saj ena ura likovne umetnosti na teden gotovo ni voda na mlin kontinuirane likovne aktivnosti učencev, poglobljene obravnave in utrjevanja likovnih pojmov, ustvarjalnih izvirnih idej in sproščenega ustvarjalnega vzdušja, pa tudi ne dobre, natančne izvedbe likovnih izdelkov učencev. Pri takšni raznolikosti učencev, s kakršno se srečujemo učitelji, sta še posebej pomembni kompetenca in zaveza vsakega izmed nas, da pri svojem delu upošteva in spoštuje enkratnost posameznika. Ključnega pomena je individualna obravnava vsakega učenca in spremljanje njegovega napredka glede na njegovo izhodiščno stanje, ki je pri vsakem učencu drugačno, saj je odvisno od učenčevega predznanja, zainteresiranosti za delo, sposobnosti, natančnosti, ustvarjalnosti, vedoželjnosti, odzivnosti itd. Vsak učitelj bi moral znotraj vsakega izobraževalnega sistema ne glede na podajano vsebino, področje poučevanja ali starost učencev stremeti k vzgajanju odgovornih, uravnovešenih, samozavestnih, kreativnih mladih ljudi (Ingalls Vanada, 2016). Likovno izobraževanje ima v tem smislu prav posebno mesto, saj je njegova naloga učenje likovnega jezika, cilj pa spoznavno-poetična uporaba tega jezika, ki mu z vso pravico pripada naziv univerzalni jezik (Selan, 2014). Čeprav se je raziskava osredotočala predvsem na eno raven likovnega jezika, to je na obravnavo prostorskih ključev, so rezultati raziskave razkrili širši problem likovnega izobraževanja. Pokazali so namreč, da bistva usvajanja prostorskih ključev (in s tem tudi drugih načel likovnega jezika) ni mogoče zajeti v nekajurno učenje posameznih prostorskih ključev, pač je treba zagotoviti kontinuirano razvijanje sposobnosti artikulacije likovnega prostora (oz. vseh ravni likovnega jezika). Raziskavo bi bilo 
zato v nadaljevanju smiselno razširiti tako, da bi se pomembnost kontinuiranega razvoja likovnega jezika še bolj razkrila. Torej bi jo bilo smiselno razširiti tudi na druga načela likovnega jezika, jo izvesti na bolj reprezentativnem vzorcu ter izvesti ocenjevanje nastalih likovnih del s široko skupino strokovnjakov.

\section{Summary}

In the article, we address an issue that can be observed in art lessons in the eighth and ninth grades of primary school in Slovenia. This issue concerns the ability to articulate the illusion of space in drawing by the use of visual gradients (e. g. perspective, light and dark modulation, size gradation etc.). Real space is a threedimensional space in which we move and orient ourselves according to body planes defined by the structure of the human body. Real space can be represented in twodimensional visual art space only by creating the illusion of a third dimension. Artists tried to solve the problem of creating the illusion of real space throughout the history of fine arts, especially in the Renaissance. The representation of the third dimension on a flat plane can only be achieved by the use of visual gradients. Therefore, the concept of visual gradients is an important part of the visual arts curriculum for eighth-grade classes in Slovenian primary school. At the age of fourteen, pupils can develop an awareness of perceptual constants that will enable them to properly understand visual gradients. However, once the pupils have acquired the knowledge of visual gradients, teachers often observe that pupils then fail to apply this knowledge in similar drawing tasks at a later time. In this study, we sought to define how eighth-graders, once having grasped the knowledge of visual gradients, use this knowledge in subsequent drawing assignments when there is no explicit demand for the use of visual gradients. During art lessons, we carried out qualitative research that consisted of two parts. The sample comprised 28 pupils in two eighth-grade groups. In the first part of the study, we informed and instructed the pupils on the visual gradients that they had to use in their drawings. In the second part, after three months, the same pupils performed another drawing task, this time without the instruction to use visual gradients. The drawings were then compared and analysed. By comparing two drawings from each pupil, we established the knowledge level of visual gradients and also how pupils applied this knowledge in the second drawing after three months. One of the key findings based on the results is that two-thirds of these pupils failed to extend their knowledge of visual gradients to the second drawing (despite having applied it in making the first drawing). This reveals to us that a single exposure to visual gradients does not lead a pupil to internalise knowledge of visual gradients or to use it spontaneously. To 
be able to spontaneously master the nature of visual art space, a pupil must undergo a longterm artistic experience with visual art space.

\section{Literatura}

Berce Golob, H. (1993). Likovna vagoja - načini dela pri likovni vagoji: Priročnik za učitelje na predmetni stopnji osnovne šole. Ljubljana: Država založba Slovenije.

Butina, M. (1995). Slikarsko mišljenje: Od vizualnega k. likovnemu. Ljubljana: Cankarjeva založba.

Butina, M. (1997). Prvine likovne prakse. Ljubljana: Debora.

Butina, M. (2000). Mala likovna teorija. Ljubljana: Debora.

Carlson, N. (2010). Psychology: the Science of Behavior. Toronto: Pearson Canada Inc.

Cox, M. (2005). The Pictorial World of The Child. Cambridge: Cambridge University.

Duh, M. in Vrlič, T. (2003). Likovna vaggoja v prvi triadi devetletne osnovne šole: priročnik za učitelje razrednega ponka. Ljubljana: Rokus.

Foster, D. H. (2011). Color Constancy. Vision Research, 51 (7), 674-700.

Freeman, N. H. (1980). Strategies Of Representation in Young Children. London: Academic Press.

Frelih, Č. (2012). Druga narava: Razdalje med videzom in obliko. V Č. Frelih in J. Muhovič (ur.), Likovno/Viqualno: Eseji o likovni in vizualni umetnosti (str. 11-26). Ljubljana: Pedagoška fakulteta Univerze v Ljubljani.

Garrigan, P. in Kellman, P. J. (2008). Perceptual Learning Depends on Perceptual Constancy. Proceedings of the National Academy of Sciences of the United States of America, 105 (6), 2248-2253.

Gillam, B. (2000). Perceptual Constancy. V A. E. Kazdin (ur.), Encyclopedia of psychology, 6 (str. 8993). Oxford: American Psychological Association and Oxford University Press.

Golomb, C. (1992). The Child's Creation of the Pictorial World. Berkeley: University of California Press.

Goolkasian, P. in Bojko, A. (2001). Location Constancy and Its Effect on Visual Selection. US National Library of Medicine National Institutes of Health, 14 (2), 175-199.

Grgurić, N. in Jakubin, M. (1996). Vizualno-likovni odgoj i obrazovanje: metodički priručnik. Zagreb: Educa.

Ingalls Vanada, D. (2016). An Equitable Balance: Designing Quality Thinking System in Art Education. International Journal of Education \&o the Arts, 17 (11), 1-21.

Jolley, R. (2010). Children and Pictures: Drawing and Understanding. Malden: Wiley - Blackwell.

Karlavaris, B. in Berce Golob, H. (1991). Likovna vagoja: priročnik za učitelje razrednega pouka. Ljubljana: Državna založba Slovenije.

Kocjančič, N., Karim, S., Kosec, M., Opačak, Ž., Prevodnik, M., Rojc, J., Velikonja, A., Zupančič, T., Kepec, M., Prevodnik, M., Tomšič Amon, B. in Selan, J. (2011). Uíni načrt. Program osnovna šla. Likovna vagoja. Ljubljana: Ministrstvo za šolstvo in šport; Zavod RS za šolstvo.

Kuroda, T. (1971). Distance Constancy. Psychologische Forschung, 34 (3), 199-219.

Lowenfeld, V. in Brittain, W. L. (1987). Creative and Mental Growth. New Jersey: Prentice - Hall.

Luquet, G. H. (1013). Les dessins d'un enfant. Étude psychologique. Paris: Librairie Félix Alcan.

Luquet, G. H. (1927). Le Dessin enfantin. Paris: Librairie Félix Alcan.

MacEvoy, S. in Paradiso, M. A. (2001). Lightness Constancy in Primary Visual Cortex. PNAS, 98 (15), 8827-8831.

Marjanovič Umek, L. (2011). Otroška risba. V L. Marjanovič Umek in M. Zupančič (ur.), Razvojna psihologija: iz̧brane teme (str. 127-156). Ljubljana: Znanstvena založba Filozofske fakultete Univerze v Ljubljani. 
Marjanovič Umek, L. in Zupančič, M. (ur.) (2004). Razvojna psibologija. Ljubljana: Znanstvenoraziskovalni inštitut Filozofske fakultete.

Matthews, J. (1999). The Art of Childhood and Adolescence: The Construction of Meaning. Philadelphia: Falmer Press, Taylor and Francis Inc.

Matthews, J. (2003). Drawing and Painting: Children and Visual Representation. London: Paul Chapman Publishing.

Matthews, M. H. (1992). Making Sense of Place: Children's Understanding of Large-Scale Environments. Hemel Hempstead: Harvester Wheatsheaf.

Muhovič, J. (2015). Leksikon likovne teorije: slovar likovnoteoretskih izrazov zustręnicami iz angleške, nemške in francoske terminologije. Celje; Ljubljana: Celjska Mohorjeva družba.

Pečjak, V. (2006). Psibološka podlaga vizualne umetnosti. Ljubljana: Debora.

Piaget, J. in Inhelder, B. (1956). The Child's Conception of Space. London: Routledge \& Kegan Paul.

Pibernik, N., Podobnik, U. in Selan, J. (2017). Likovna nadarjenost in likovnojezikovni kriteriji za ugotavljanje kompleksnosti likovnih izdelkov učencev. V T. Devjak in I. Saksida (ur.), Kakovost in ocenjevanje znanja (str. 181-202). Ljubljana: Pedagoška fakulteta Univerze v Ljubljani.

Rački, T. (2010). Vešcine risanja 3: Majhne skrivnosti velikih mojstrov. Ljubljana: Javni sklad Republike Slovenije za kulturne dejavnosti.

Selan, J. (2013). Likovni jezik kot temelj likovne vzgoje in izobraževanja. Vzgoja in izobraževanje, 4/5 (44), 41-47.

Selan, J. (2014). Temeljni namen likovnega izobraževanja: likovni jezik in likovna kompetenca. V T. Devjak (ur.), Sodobni pedagoški iz:ivivi v teoriji in praksi (str. 371-388). Ljubljana: Pedagoška fakulteta Univerze v Ljubljani.

Sternberg, R. (2006). Cognitive Psychology. Belmont: Wadsworth, Cengage Learning.

Strauss, M. (2007). Understanding Children's Drawing: Tracing the Path of Incarnation. Forest Row: Rudolf Steiner Press.

Tanay, E. R. (1988). Likouna kultura u nižim raẓedima osnovne škole: priručnik qa nastavnika. Zagreb: Školska knjiga.

Thomas, G. V. in Silk, A. M. J. (1990). An Introduction to the Psychology of Children's Drawings. Hemel Hemstead: Harvester Wheatsheaf.

Tomšič Čerkez, B. (2011). Razvoj prostorskih predstav v svetu novih medijev. Revija za elementarno izobraževanje, 4 (3), 19-33.

Trawick-Smith, J. (2013). Early Childhood Development: A Multicultural Perspective. London: Pearson Education Limited.

Trstenjak, A. (1978). Clovek in barve. Ljubljana: Univerzum.

Waber, D. P. in Holmes, M. J. (1985). Assessing Children's Copy Productions of the Rey-Osterrieth Complex Figure. Journal of Clinical and Experimental Neuropsychology, 7 (3), 264-280.

Wenham, M. (2003). Understanding Art: a Guide for Teachers. London: P. Chapman: Thousand Oaks.

\section{Authors}

\section{Barbara Lapuh, MA.}

Jurij Selan, PhD

University of Ljubljana, Faculty of Education, Kardeljeva ploščad 19, 1000 Ljubljana

Associate Professor, Faculty of Education, Kardeljeva ploščad 19, 1000 Ljubljana, e-mail: jurij.selan@pef.uni-lj. 